\title{
Cognitive Dysfunctions In School-Age Of Children With Epilepsy
}

\author{
Mimoza Maloku Kuqi*; Eglantina Dervishi** \\ *Clinical University Center of Pristina, Kosovo \\ **Department of Psychology and Pedagogy, Faculty of Social Sciences, University Of \\ Tirana, Tirana, Albania
}

\begin{abstract}
The Purpose Of The Present Article Is To Explore And Analyze The Cognitive Dysfunctions On School-Age Children Suffering From Epilepsy. A Second Aim Is To Elicit Inferences On The Factors, Nature And Comorbidity Of Idiopathic Epilepsy Typologies With Cognitive Deficits In These Subjects.

The Method Used In The Present Study Is Of A Retrospective And Comparative Type.

The Results Of The Metanalytical Process Will Be Determined Through Examination Of Specific Literature And Dynamic Analysis Of The Nature And Association Of Epilepsy With Cognitive Dysfunctions In This Group-Age.

At The End Of This Article, Some Considerations Will Be Articulated On The Didactic, ReEducation And Forms Of Effective Psycho-Education In Order To Modify Not Only The Curricular But Also The Extracurricular Dynamics Of These Subjects.
\end{abstract}

Keywords: Epilepsy Types, Cognitive Dysfunctions, School- Age Childre, Psychoeducation 


\section{Introduction}

Epilepsy Is A Neuropsychological Disease Known Since The Earliest Times, And The Dynamism Of Its Development Has Always Been Linked By Mystery And Curiosity. Even Nowadays, In Addition To Developing Scientific Knowledge, Epilepsy Is Accompanied By A Series Of Collective Prejudices That Make Life Difficult For The Individual Suffering From It And Qualitatively Compromise The Psychic Balance Of Normal Life. Although Epileptic Seizures Can Be Overseen More Effectively In Today's Clinic, For Many Patient Individuals, And Especially For Infants, There Are Numerous Difficulties That Strongly Affect Their Lifestyle. Similar Difficulties Arise In Terms Of Cognitive Functions That Can Dimensionalally And Permanently Alter Intelligence Development And Cause Specific Disability.

In A Narrow Spectrum, According The Definitions Given By The International Leagues Against Epilepsy (Ilae) And The International Bureau For Epilepsy (Ibe), (Cited By Fisher Et.A1, 2005), Epileptic Seizures And Epilepsy Can Often Occur In Overlapping Conditions To Each -Other.

The Epileptic Seizure Represents A Transient Event With Signs And Symptoms Associated With Abnormal, Excessive Or Synchronous Neuronal Brain Activity. Epilepsy Is The Definition Of That Brain Disorder That Is Characterized By A High Predisposition To Develop Epileptic Seizures With Neurobiological, Cognitive, Psychological And Social Consequences On The Affected Individual. Epilepsy Can Affect All Age Groups But The Highest Age Frequency Affected By This Disorder Is That Of Childhood And School Age. Some Forms Of Epilepsy End At The School Age, But If Left Professionally Untreated, Epilepsy Can Have A Chronic And Often Life-Long Progression.

From The Pathophysiological Aspect Of Development, Epilepsy Is Characterized By A Sudden, Paroxysmal Disorder That Is The Result Of Pathological Depletion Of Brain-Neuron 178 
Clusters. As Can Be Understood From This Fisher's Definition, The Neuropsychological And Behavioral Aspects Of Pathology Have A High Impact On The Occurrence Of Epilepsy And Recurrence Of Epileptic Seizures.

\section{Classifying Epilepsy In The Shcool-Aged Children}

Epilepsy Is Not A Single Condition, But Rather A Group Of Pathologies United By The Association With An Increased Predisposition To The Appearance Of Epileptic Seizures.This Has Made It Particularly Difficult To Draw Up A Complete Classification, Which Have Been Reviewed Over Time Until Their Last Partial Modification In The 2010. Thus, A Division Between The Epileptic Conditions Could Refer To:

1. Epileptic Seizures. Crises Can Be Divided Into Two Main Types: Partial Crises, Or Focal, According To The Most Recent Terminology, In Which A Focal Or Localized Onset Can Be Identified, And Generalized Crises, Which Are Bilateral , Symmetrical And Without Localized Onset. Neuronal Discharges Seem To Start Simultaneously And Diffusedly In Both Hemispheres. Focal Seizures Can Then Spread To The Whole Cerebral Cortex, Giving Rise To The So-Called "Secondarily Generalized Seizures". The Generalized Seizures Are Then Divided Into Two Types: Convulsive And NonConvulsive. The Most Common Seizure Type Is The Tonic-Clonic Crisis , Historically Defined As The "Great Evil". The Classic Generalized Non-Convulsive Crises Consist Of Short Episodes Of Suspension Of Consciousness In The Absence Of Significant Motor Manifestations, Or Minor Motor Phenomena Such As Short Myoclonic, Atonic Or Tonic Crises (Ropper And Brown, 2005).

2. Epileptic Syndromes. The "Epileptic Syndrome" Or "Electro-Clinical Syndrome", It Is Refered To A Specific Complex Of Clinical Manifestations, Electroencephalographic Characteristics And Epidemiological Elements That Contribute To Defining A Distinct And Clinically Recognizable Pathology, With Therapeutic, Prognostic, And 
Neuropsychological And Neuroimaging Studies (Panayiotopoulos, 2010). For The Youth-Potential Affected,We Can Essentially Distinguish Three Main Categories Of Syndromes Based On Etiology :

- Idiopathic Syndromes, Due To Unidentified Cause, Therefore Believed To Be Of A Genetic Nature;

- Symptomatic Syndromes, Manifestation Of An Organic Or Structural Cause Represented By A Pathogenic Noxa Affecting The Central Nervous System, Such As Perinatal Hypoxic-Ischemic Encephalopathy, Chronic Ischemic Vascular Encephalopathy, Neoplasms Etc;

- Cryptogenic Syndromes, Manifestation Of A Presumed But Not Identified Lesion Affecting The Nervous System Central.

\section{Dysfunctions Of The Cognitive Structure In School-Aged Children Affected By Epilepsy}

The Affection Of The Cognitive Field In School-Age Epileptic Children Also Reveals Some Complex And Heterogeneous Aspects. Neuropsychological Symptoms Are Heterogeneous As Are Epileptic Syndromes Themselves And Include Language, Memory Or Attention Deficits, Visual-Spatial Deficits, And Learning Disorders. Cognitive-Behavioral Problems In Children Affected By Epilepsy Have Been Documented In The Literature Since The 19th Century And Are Still An Issue Of Significant Attention (Esquirol, 1838; Romberg, 1853). The Nature Of The Relationship Of Epilepsy To Cognitive And Learning Disorders Can Also Be Highlighted At These Specific Situations: Epilepsy And Learning Disorders Can Be The Consequence Of The Same Cerebral Impairment, And Epilepsy Can Cause A Cerebral Lesion That Subsequently Develops A Learning Disorder .

Young Age-Related Epilepsy Can Affect Learning By Developing An Episodic Dissociation Of Neural Activity And High Cognitive Functions. This Episodic Dissociation May Be Responsible For The Appearance Of Transient Cognitive Deficit Associated With 180 
Epileptic Discharges (Aarts Et.Al, 1984). Most Neuropsychological Research Has Focused On Cognitive Deficits In Forms Of Focal Epilepsy, Such As Frontal Lobe Epilepsy Or Temporal Lobe Epilepsy, Due To The Direct Association Of These Types Of Epilepsies With Cognitive Disorders.

After The 2015, Scientific Interest Has Grown To The Neuropsychological Analysis Of Generalized Idiopathic Syndromes, Which Are Now Raising Their Spread And Diffusions. Aldenkamp Et Al. (2004) Have Suggested That Children With Epilepsy Are Affected By The Presence Of Specific Cognitive Problems Such As Short-Term Memory Deficits, Attention Deficits, And A Decline In School Performance. In A More Synthesized View, Other Authors Have Provided Their Analysis Of The Dynamics Of Affective Cognitive Functions In Pediatric School-Age Children As A Result Of Epilepsy. Cornaggia Has Argued That Cognitive Functions Relate Primarily To The Capacity Of The Human Brain To Process All Information Coming From The External And Internal World And Behavioral Programming As A Result Of These Processes.

This Capacity Include The Ability To Maintain Contacts With The External World,Psychic Vigilence And The Ability To Select And Focus Information Through Attention And Data Memory(Cornaggia, 2001). In A Synthesized Form, In The Cognitive Areas Affected By Pediatric Epilepsy, We Might Include:

a. Executive Functions, Or The Set Of Mental Processes Needed To Process CognitiveBehavioral Schemas In A Response To New Or Changing Environmental Conditions (Owen, 1997). These Executive Functions Are Connected Firstly To Cognitive Flexibility And The Ability To Plan. Solutions To Cognitive Issues. These Include The Ability To Program, Modify And Verify An Action To Achieve A Specific Goal, Such As The Ability Of The Young Person To Plan And Represent At A Mental Level Without Requiring Memorization Of The Stages Necessary To Accomplish 
This Activity. The Cognitive Functions Of These Categories Of Subjects Affected By Epilepsy Are Essentially Influenced By Forms Of Orientation And Organization In Complex And Conflict Situations, Which, Depending On The Age Of The Juvenile, May Include Various Capacities. Such Categories May Involve:The Ability To Plan And Evaluate Efficient Strategies For Problem Solving And Cognitive Flexibility; Control Of Inhibitory Feedback And Decision-Making Processes That Support The Selection Of Specific Responses To Environmental Requirements; The Attention Control Related To The Explicit Inhibitory And Information Activity Abilities ;Working And Semantic Memory That Are Fully Activated In The Performance Of A Task; Verbal Fluency, Visual-Perceptual And Visual-Spatial Capacity. Thus The Disorders Associated With These Executive Functions Can Occur With A Multitude Of Issues In The Subject's Daily Life And Especially In His Or Her Academic Life. Dysfunctions May Include Inappropriate Social Behavior, Difficulty In Decision Making And Judgment, Difficulty In Developing, Following And Modifying Plans, Difficulty In Organizing, Lack Of Concentration And Difficulty In Different Dimensions Of Memory.

b. Visual-Spatial Capacity, Which Involves A Set Of Processes That Allow The Individual The Right Of Interaction With The External World. These Skills Consist On The Ability To Integrate Information Coming From The Perceptual Space To Develop Some Spatial Coordinating Points That Regulate The Organization And Use Of The Materials Needed To Perform The Task. These Skills Are Also Embedded In A Multitude Of Practical Tasks Of Daily Life. Visual-Spatial Deficits Can Thus Be Defined As A Misconception Of Spatial Relationships Between Objects Or Between An Individual And An Object That Do Not Carry A Homogeneous Line Of Expression But Appear In Complex Forms With Non-Verbal Attitude Difficulties; Difficulties In Coping Or Drawing And Difficulties In Creating Grapho-Motor Sounds; Difficulties In Spatial Organization Of Holding A Sheet Of Paper And Line 
Writing; Difficulties In Written Calculations And Geometry; Difficulties In Reading And Visual Adjustment.

c. Verbal Memory, Which In The Cognitive Psyche Refers To The Memory Of Words And Other Linguistic Abstractions;

d. Spatial Memory, Which Means That Part Of The Memory That Is Responsible For Recording Environmental Information And Spatial Orientation. Included Here Are Both Semantic And Short Or Long-Term Memory. Semantic Spatial Memory Allows The Young To Record And Process All Temporary Information In Order To Achieve An Objective. Short-Term Spatial Memory Allows Different Environments To Be Remembered And Identified As Well As To Record Spatial Relationships Between Objects. Short-Term Memory Represents An Superior Level As It Allows The Individual To Record And Remember The Characteristics Of His Or Her Cognitive Map.

e. Language And Linguistic Capacities. This Category Includes The Skills Of Understanding And Using A Complex, Word-Based Communication System Which Consists On The Ability To Organize Words And Develop Their Expression And Meaning. Throughout The Semantic System Are Represented The Conceptual Knowledge Related To The Information On Their Significance And Organized By Conceptual Categories (Animals, Parts Of The Body, Places). Other Research By Troyer Et Al. (1998) Have Shown That In Subjects With Lesions In The Frontal Lobus, Phonemic Verbal Fluency Is Understood While Semantic Is Relatively Reserved.

The Pattern Of Cognitive Deficits Associated With Epilepsy At Developmental Ages Carries A Direct Correlation With The Localization Of Cerebral Cortex Functions. This Phenomenon Is Mostly Expressed In Cases Of Focal Epileptogenic Lesions. In A More Detailed Form, The Study Of Cognitive And Behavioral Comorbidity Of Epilepsy Is Complicated By 
Numerous Risk Factors That May Influence And Modify Clinical Observations Of Neurocognitive Performance. Kwan, Brodie (2001) And Lee (2010) Have Specifically Elaborated These Factors Linked With The Occurrence Of Cognitive Disorders. Hermann And Whitman (2011) Subsequently Grouped These Risk Factors Into Three Categories:

- Neurobiological Factors, Including Neuropathology And Esiology Of Epileptic Syndrome And Many Clinical Variables (Age Of Onset, Duration Of Disease, Seizure Typology, Therapeutic Control, And Presence Of Epileforms Abnormalities With Epilepsy);

- Psychosocial Factors Associated With Chronicity Of Illness

- Iatrogenic Factors Associated With The Typology Of Therapy, The Amount Of Medicines And Their Effects, Whether In Terms Of Neurotransmitter Modification And Metabolic Effects

The Functional Cerebral Areas As Represented By The Brodmann's Map (Cited By Loukas Et Al., 2011) Divides The Cerebral Cortex Into 47 Domains To Which Certain Cerebral Functions Respond. In School Age, The Most Common Partial Epilepsies Comes From The Middle Temporal Lobe Structures And Are Thus Associated With Learning And Memory Disorders. Right Parietal Lobe Lesions Are Associated With Visual-Spatial Information Processing Deficits, Whereas Left Parietal Lobe Lesions May Exhibit Impairment In The Linguistic, Reading, Writing, And Computing Tasks. The Frequency, Gravity, And Totality Of Seizures Across Cycles Adversely Affect Children's Cognitive Deficits. The Literature Has Recommended That Early Onset And Duration Of Active Disease (Epilepsy) Are Associated With A Worsening Of Cognitive Deficits. 


\section{Conclusions}

It Is Equally Important To Elicit Inferences About Didactic Re-Education Discourse And Forms Of Effective Psychoeducation For The Modification Of The Subject Lines Not Only In The Curricular But Also The Extra-Curricular Domains Of These Subjects. Re-Education Is The Process Of Assisting A System To Re-Adapt Some Of The Previously Held Dimensions To Be Effectively And Autonomously Exercised By Subjects In The Future. This Process Plays An Even More Significant Role In People Who Have Difficulties Or Have Lost Their Cognitive Abilities Due To Epilepsy Or Epileptic Seizures To Encourage Specialists To Conceive Of Alternative Ways Of Inter- And Extra-Curricular Intervention And To Acquire Some Specific Skills. Throughout Development. Children With Cognitive Impairment As A Result Of Epilepsy May Encounter Difficulties In One Or More Abilities, So It Is Convenient To Identify, For Each Case, Small Feasible Objectives That Children Can Practice And Obtain By Repeating Them. The Given Task Is Very Important Especially In The Beginning Stages Of These Activities, To Avoid Frustration And To Achieve The Objectives.

A Good Psychoeducation Program And The Promotion Of The Curricula Towards Acquiring A Competencies In These Children To Reinforce And Refine Them Is Of A Very Significant Role.Targeted Interventions Of Clinical Psychology And Neuropsychology Specialists In These Populations Are Processes Of Support Towards Special Education Techniques For Their StepBy-Step Coaching.

\section{References}

1. Aarts, J., Binnie, C. D., Smith, A. M., \& Wilkins, A. J.(1984). Selective Cognitive Impairment During Focal And Generalized Epileptiform Eeg Activity. Brain, 107, 293308

2. Aldenkamp, A. P., \& Arends, J. (2004). Effects Of Epileptiform Eeg Discharges On Cognitive Function: Is The Concept Of "Transient Cognitive Impairment" Still Valid? Epilepsy

Behav, 5 Suppl 1, Pp. 25-34. 
3. Aldenkamp, A. P., \& Arends, J.(2004). The Relative Influence Of Epileptic Eeg Discharges,Short Nonconvulsive Seizures, And Type Of Epilepsy On Cognitive Function.Epilepsia, 45, 54-63

4. Cornaggia,M.Cesare \& Gobbi,G.(2001)Learning Disability In Epilepsy:Definitions And Classifications, Wiley Journal Of Epilepsia,Vol.421 ${ }^{\text {st }}$ Issue,Pg.2-5,Usa

5. Esquirol, E. (1838). Des Maladies Mentales. Jb Balliere, P. 284.

6. Fisher R. S., Boas W. V. E., Blume W., Elger C., Genton P., Lee P., Engel J. (2005). Epileptic Seizures And Epilepsy: Definitions Proposed By The International League Against Epilepsy (Ilae) And The International Bureau For Epilepsy (Ibe). Epilepsia 46(4):470-472

7. Hermann B., Whitman S. (1984). Behavioral And Personality Correlates Of Epilepsy: A Review, Methodological Critique, And Conceptual Model. Psychol Bull 95(3):451-97

8. Lee G. (2010). Neuropsychology Of Epilepsy And Epilepsy Surgery. Oxford University Press, Usa.

9. Loukas,M. , Pennell,Ch.,Groat,Ch. ,Tubbs,Shane R.,Gadol-Cohen A.Aaron (2011)Korbinian Brodman And His Contributions To Mapping The Cerebral Cortex,Neurosurgery,Vol.68, $1^{\text {st }}$ Issue,Pg.6-11,Oxford Academic

10. Kwan P., Brodie M. J. (2001). Neuropsychological Effects Of Epilepsy And Antiepileptic Drugs. The Lancet 357(9251):216-222.

11. Owen A. M. (1997). Cognitive Planning In Humans: Neuropsychological, Neuroanatomical And Neuropharmacologicalperspectives. Progress In Neurobiology 53(4):431-450.

12. Panayiotopoulos C., Tahan R., Obeid T. (1991). Juvenile Myoclonic Epilepsy: Factors Of Error Involved In The Diagnosis And Treatment. Epilepsia 32:672-

13. Panayiotopoulos C. (2010). A Clinical Guide To Epileptic Syndromes And Their Treatment. Springer

14. Romberg, M. H. (1853) A Manual Of The Nervous Diseases Of Man. London:Syndenham

Society

15. Ropper A., Brown R. (2005). Adams E Victor, Principi Di Neurologia. Mcgraw-Hill Companies

16. Troyer A. K., Moscovitch M., Winocur G., Alexander M. P., Stuss D. (1998). Clustering And Switching On Verbal Fluency: The Effects Of Focal Frontal- And Temporal-Lobe Lesions. Neuropsychologia 36(6):499-504 